\title{
Organophosphate Resistance in Aedes aegypti: Study from Dengue Hemorrhagic Fever Endemic Subdistrict in Riau, Indonesia
}

\author{
Suri Dwi Lesmana*1, Esy Maryanti ${ }^{1}$, Elva Susanty ${ }^{1}$, Dedi Afandi ${ }^{2}$, \\ Wida Harmas ${ }^{3}$, Delly Noer Octaviani ${ }^{3}$, Iskandar Zulkarnain ${ }^{3}$, \\ Muhammad Agung Bariq Pratama ${ }^{3}$, Mislindawati Mislindawati ${ }^{1}$
}

\begin{abstract}
Background: Dengue hemorrhagic fever (DHF) is a significant health problem. The high number of cases requires preventions, including controlling the dengue vector, Aedes aegypti mosquito. One of the control methods is the use of insecticides containing organophosphate. This study aims to detect organophosphate resistance in Aedes aegypti from DHF endemic subdistrict, Riau, Indonesia by a sensitivity test of temephos and 5\% malathion and measuring the activity of non-specific alpha and beta esterase enzymes.

Methods: This observational study determined Aedes aegypti resistance from larvae to adult in one DHF endemic subdistrict in Riau, Indonesia. The bioassay was used for temephos sensitivity of Aedes aegypti larvae. The LC99 value was analyzed using probit and compared with the diagnostic value from WHO. The WHO susceptibility test was conducted to determine 5\% malathion resistance from adult mosquitoes. The mortality of less than $90 \%$ was declared as resistant. Measurement of alpha and beta esterase levels used Lee's microplate assay technique based on visual identification and absorbance value (AV).

Results: The results showed that Aedes aegypti were resistant to temephos. It also showed that adult mosquitoes were resistant to $5 \%$ malathion. Based on the alpha esterase activity test, it was found that most of the mosquitoes showed very sensitive meanwhile, based on the beta esterase activity test, most of the mosquitoes were moderate resistance.

Conclusions: This study suggests that Aedes aegypti population from DHF endemic subdistrict in Riau, Indonesia are indicated to develop resistance to organophosphate.
\end{abstract}

Keywords: Aedes aegypti, Dengue Hemorrhagic fever, Organophosphate, Resistance.

\section{Introduction}

Dengue hemorrhagic fever (DHF) is still a world public health problem, especially in tropical and subtropical regions, including Indonesia as one of the dengue-endemic countries. Dengue hemorrhagic fever is a disease caused by the dengue virus, which has the fastest spreading in the world (1). This disease can cause death due to bleeding and hemodynamic disorders (2). The primary vector of DHF is the mosquito called Aedes aegypti (Ae. aegypti) while the potential vector is Aedes albopictus (Ae. albopictus). These mosquitoes are also vectors of chikungunya, Yellow fever, and Zika virus $(3,4)$.

The incidence of dengue has increased worldwide in recent years. The World Health Organization (WHO) reports that the incidence of dengue has increased drastically in the last 50 years and virus infection continues to spread in various countries. WHO data states that the 
number of dengue cases globally is around 390 million cases of dengue infection each year. There are 3.9 billion people in 128 countries who are at risk of contracting the dengue virus infection (2).

Available data from National Disease Surveillance System have indicated an increasing trend of dengue incidence in Indonesia over the past 50 years. Incidence rates appear to be cyclic, peaking approximately every 6 to 8 years (5). Riau Province is one of the provinces with IR 59.18 which is higher than the national average in 2019, and this number has increased dramatically from the previous year (13.47 per 100.000 population) which Payung Sekaki is the regional group with the highest cases in Pekanbaru.

DHF cases require prevention efforts by breaking one of the epidemiological triangular chains, including controlling the dengue vector, the Ae. aegypti mosquito $(4,6)$. Currently, vector control efforts can be carried out in various ways, including the Eradication of Mosquito Nests and the use of insecticides. The government and society generally prefer to use insecticides to control the dengue vector mosquito population. The main reasons for using insecticides to be the leading choice are ease of use, ease of obtaining and the results are immediately visible results (7).

The insecticide used to eradicate mosquitoes in government programs is an insecticide with an active organophosphate ingredient. Organophosphate insecticides, especially temephos and malathion are always used to eradicate $A e$. aegypti mosquitoes in the larval and adult stages (8). Malathion is used extensively to kill insects in the health, agriculture, livestock, and household fields. Malathion has high toxicity to insects while its toxicity to mammals is relatively low, so it is widely used (9). Malathion is also used for fogging, a government program for dengue fever prevention since 1973 (7).

Using one type of insecticide for a long time or using it continuously can cause resistance or immunity to Ae. aegypti (10,11). Resistance happened because Ae. aegypti and other dengue virus vectors can develop an immune system against insecticides that are often used (12). Currently, insecticide resistance is a global phenomenon felt by all developed and developing countries. There have been many studies on the susceptibility status of Ae. aegypti against organophosphates and showed different results consisting of sensitive, tolerance, and resistance.

Based on research conducted in Pulogadung in 2013, it was shown that the most of $A e$. aegypti has been sensitive to malathion. Meanwhile, research in Tanjung Priok, North Jakarta, in 2007 obtained results mostly of Ae. aegypti, which has been resistant to the organophosphate (8). Not only in Indonesia, but resistance to organophosphates has also been reported from around the world. Based on research by Santos et al. In Brazil, it was reported that $A e$. aegypti resistance against temefos through susceptibility tests and enzymatic biochemical tests (13). There are differences in sensitivity status in each region and country. In Mexico resistance Ae. Aegypti was reported against synthetic pyrethroid group insecticides, while organophosphates can still be used (14).

In general, the mechanism of insect resistance to insecticides is classified into three groups, namely cuticular resistance (decreased penetration), metabolic resistance, and changes in the target side (a genetic mechanism). The susceptibility test of the mosquitoes can show these. In metabolic resistance, there is a change in the enzyme, both qualitatively and quantitatively, that metabolizes the insecticide before it reaches the target side. Esterase, glutathione $\mathrm{S}$ transferase, and oxygenase are three enzymes included in this group. Esterase is hydrolase enzyme that splits esters into acid and alcohol (12). As in humans, Glutathione Stransferases (GSTs) catalyse the detoxifying reaction of polycyclic aromatic hydrocarbons (15).

The enzymes play the most role in $A e$. aegypti resistance to organophosphate is an esterase. The esterase enzyme hydrolyzes the ester chain in the organophosphate thereby eliminating its toxicity (16). The non-specific esterase enzymes are identified to consist of $\alpha$ 
and $\beta$ esterases. This enzyme activity mechanism is an essential pathway in expanding resistance worldwide (17). Biochemical tests on resistant Ae. aegypti mosquitoes in Venezuela showed a strongly coloured band on electrophoresis which is esterase A4 which is not found in sensitive mosquito strains. The same was reported from the biochemical tests on Ae. aegypti from Santiago Cuba where the identified enzyme is esterase $\beta$ (18).

Insecticides that have been resistant can reduce or even eliminate the effects of these insecticides to kill Ae. aegypti mosquitoes. This causes the Ae. aegypti is challenging to eradicate, so the incidence of DHF is challenging to reduce. Based on this background, the authors are interested in researching the detection of resistance to Ae. aegypti against organophosphate insecticides in DHF endemic sub-districts, Payung Sekaki, Pekanbaru Riau, Indonesia.

\section{Materials and Methods}

The observational research was conducted in February - October 2020 located in a dengueendemic area in Pekanbaru Riau, Labuh Baru Timur Village, Payung Sekaki District. There were four spots of DHF high case. Preparation of test larvae was carried out at the Parasitology Laboratory of Faculty of Medicine, Universitas Riau, Indonesia. This study has passed the ethical review of the Medical and Health Research Ethics Unit of the Faculty of Medicine,
Universitas Riau with register number B / 104 / UN19.5.1.1.8 / UEPKK / 2020. Based on the Ministry of Health criteria for resistance testing sites (24), Samples were taken from the houses in the four spots of Payung Sekaki district that the total number of houses taken were 100 houses (figure 1). Purposive sampling was used to determine the house where the larvae were collected, with the criteria being that the house contained breeding places of Ae. aegypti larvae.

Furthermore, the larvae were obtained and identified as Ae. aegypti. Furthermore, the larvae were reared in an insectary at $28{ }^{\circ} \mathrm{C}$ and $80 \% \mathrm{RH}$ with 12:12 day: night. The first- generation larvae were selected by random sampling of 150 larvae to carried out the resistance test against temephos and enzymatic esterase test. Furthermore, the first-generation larvae that were not tested were colonized into adults for the susceptibility test to $5 \%$ malathion.

\section{Sensitivity test to temephos}

The sensitivity test began with the determination of the test concentration. A preliminary test has been carried out with a temephos concentration of 0 (as negative control); $0.001 \mathrm{ppm} ; 0.01 \mathrm{ppm}$; $0.1 \mathrm{ppm} ; 10 \mathrm{ppm} ; 100 \mathrm{ppm}$ of temephos. The preliminary test aimed to obtain an estimate of the diagnostic concentration. At each concentration, 10 larvae were inserted and each was repeated twice. Larval mortality was observed after 24 hours. Furthermore, probit analysis was carried out to determine LC10 and LC100.



Fig. 1. Map of Payung Sekaki District with Four Sampling Spot. 
The sensitivity test's total concentration was in the range of $\mathrm{LC}_{10}$ and $\mathrm{LC}_{100}$ from the preliminary test. The concentration tests for temephos were 0 ppm as control; 0.003; 0.02; $0.04 ; 0.06 ; 0.1$. At each concentration, 25 larvae were inserted and each was repeated twice. Larval mortality was observed after 24 hours. To determine the resistance status of Ae. aegypti to the organophosphate was analyzed using probit software. Furthermore, the LC99 value that has been obtained was compared with the diagnostic value of resistance to temephos from WHO ( $\leq$ $0.02 \mathrm{ppm})$ (19).

\section{Bioassay Test}

Adult insecticide susceptibility bioassays were carried out using WHO test kits for an impregnated $5 \%$ malathion paper. Before exposure, the initial maintenance was conducted in six tubes with twenty-five non-blood fed adult females aged 2-3 days for one hour. After initial maintenance, the mosquitoes were exposed to the diagnostic concentration of $5 \%$ malathion impregnated paper respectively for 1 hour in by four replicates and two replicates with controls only to risella oil. Observe every 5, 10, 15, 20, 30 and 60 minutes. The mortality was recorded at the end of 24 hours holding period $(20,21)$. If the mortality's control is between 5 to $20 \%$, data must be corrected using the Abbot formula. If the mortality control is $>20 \%$, the study should be repeated. the level of mosquito susceptibility is determined based on the percentage of mosquito mortality after 24 hours. Mortality of test mosquitoes $>98 \%$ is declared susceptible, mortality 90 - $<98 \%$ is suspected resistant, and $<90 \%$ is resistant (20).

\section{Biochemical Test}

The biochemical test of nonspecific esterase is based on Lee's procedure (22). One hundred and fifty larvae were homogenized individually in $0.5 \mathrm{ml}$ cold PBS $(0.02 \mathrm{M} ; 7 \mathrm{pH})$ using micro pestle. With a micropipette, $50 \mu \mathrm{l}$ of the clear homogenate was transferred to a microplate, where two replicates for each $\alpha$ esterase and $\beta$ esterase. Fifty $\mu 1$ each $\alpha$ and $\beta$ naphthyl acetate solution $(6 \mathrm{gr} / \mathrm{L}$ in ethanol dissolved in PBS with
$1 \%$ concentration) as substrate was added and left for 60 seconds. Fifty $\mu \mathrm{l}$ fast B blue salt solution $(150 \mathrm{mg}$ fast $\mathrm{B}$ blue salt in $15 \mathrm{ml}$ aquadest and $35 \mathrm{ml}$ sodium dodecyl sulphate $5 \%$ (W/V)) was used as a coupling reagent, and the colour changed immediately after 10 minutes. It turned to green until blue in $\alpha$ esterase activity and turned to dark pink in $\beta$ esterase activity. The reaction was stopped by adding $50 \mu 110 \%$ acetic acid into each well. The intensity of the final colour is an esterase activity indicator. A microplate reader also scanned the intensity of the final colour at $450 \mathrm{~nm}$ wavelength.

The susceptibility status of mosquitoes based on $\alpha$ esterase activity was determined based on the absorbance value (AV), where the AV value of $0-0.7$ is expressed as very sensitive, $0.7-0.9$ as moderate resistance, and $>0.9$ as highly resistant. while on $\beta$ esterase activity with AV 0 0.4 as very sensitive; $0.4-0.6$ as moderate resistance and $>0.6$ as highly resistant.

\section{Results \\ Sensitivity Test to Temephos}

From the preliminary test was found that $\mathrm{LC}_{0}=0$ ppm and $\mathrm{LC}_{100}=0.1 \mathrm{ppm}$, while the $\mathrm{LC}_{10}$ after being analyzed using probit analysis showed $0.003 \mathrm{ppm}$. From probit analysis was found that the $\mathrm{LC}_{50}$ value was $0.069 \mathrm{ppm}$ and the $\mathrm{LC}_{99}$ value was $0.185 \mathrm{ppm}$. The $\mathrm{LC}_{99}$ value obtained was compared with the diagnostic value for resistance based on WHO on $0.02 \mathrm{ppm}$. We found The $\mathrm{LC}_{99}$ was above $0.02 \mathrm{ppm}$ from the study, and it was stated as resistant.

\section{Bioassay Test}

There were no mosquitoes who died in either the control group or the test group at the initial maintenance for 1 hour before carrying out insecticide exposure. Observation of the Ae. aegypti in one hour due to exposure to $5 \%$ malathion insecticides carried out at 5, 10, 15, 20,30 , and 60 minutes to determine the number of mosquitoes that fainted (knockdown) during exposure to insecticides. Observing mosquitoes in the first one hour that experienced knockdown can be seen in Table 1 . 
After 1 hour of exposure, the mosquitoes were transferred to a holding tube for 24 hours of recovery. An assessment of the number of mosquitoes that died or came back to life after the knockdown. The results of observations of mosquito mortality 24 hours after insecticide exposure can be seen in Table 2.
Based on data in Table 2, according to WHO criteria which is mosquito mortality 24 hours after insecticide exposure $<90 \%$ is resistance. So, the sensitivity status of Ae. aegypti from 5\% malathion in Payung Sekaki District, stated as resistant.

Table 1. Number of Aedes aegypti Knockdown After One Hour 5\% malathion Exposure.

\begin{tabular}{lcccccc}
\hline \multirow{2}{*}{ Tubes } & \multicolumn{5}{c}{ Number of knockdown mosquitoes (minute-) } \\
\cline { 2 - 7 } & $\mathbf{5}$ & $\mathbf{1 0}$ & $\mathbf{1 5}$ & $\mathbf{2 0}$ & $\mathbf{3 0}$ & $\mathbf{6 0}$ \\
\hline Control 1 & 0 & 0 & 0 & 0 & 0 & 0 \\
Control 2 & 0 & 0 & 0 & 0 & 0 & 0 \\
Mean & 0 & 0 & 0 & 0 & 0 & 0 \\
\hline Test 1 & 0 & 0 & 1 & 3 & 7 & 7 \\
Test 2 & 0 & 0 & 1 & 3 & 6 & 7 \\
Test 3 & 0 & 0 & 0 & 1 & 4 & 6 \\
Test 4 & 0 & 0 & 2 & 5 & 7 & 8 \\
Mean & 0 & 0 & 1 & 3 & 6 & 7 \\
\hline
\end{tabular}

Table 2. Observation of Mosquitoes Mortality.

\begin{tabular}{|c|c|c|c|c|c|c|c|c|c|c|c|c|}
\hline \multirow{3}{*}{ Time } & \multicolumn{8}{|c|}{$\begin{array}{c}\text { Number of Deaths } \\
\text { in Test Group }\end{array}$} & \multicolumn{4}{|c|}{$\begin{array}{l}\text { Number of Deaths } \\
\text { in Control Group }\end{array}$} \\
\hline & \multicolumn{2}{|c|}{ Tube 1} & \multicolumn{2}{|c|}{ Tube 2} & \multicolumn{2}{|c|}{ Tube 3} & \multicolumn{2}{|c|}{ Tube 4} & \multicolumn{2}{|c|}{ Tube 1} & \multicolumn{2}{|c|}{ Tube 2} \\
\hline & $\mathrm{n}$ & $\%$ & $\mathrm{n}$ & $\%$ & $\mathrm{n}$ & $\%$ & $\mathrm{n}$ & $\%$ & $\mathrm{n}$ & $\%$ & $\mathrm{n}$ & $\%$ \\
\hline 24 hours after exposure & 6 & 24 & 8 & 32 & 7 & 28 & 7 & 28 & 0 & 0 & 0 & 0 \\
\hline 24-hour mortality rate & & & & & $28 \%$ & & & & & & & \\
\hline
\end{tabular}

\section{Biochemical Test}

Based on the results of biochemical tests can be seen as an increase in esterase activity in Payung Sekaki District. There was a green discolouration of $\alpha$ esterase and pink colour of $\beta$ esterase to varying
Identifying resistance by visual has a high subjectivity level, so further examination is needed to determine the degree of absorbance value (AV). The $\alpha$ and $\beta$ esterase test results based on the AV value can be seen in Table 3 .

Table 3. The results of $\alpha$ and $\beta$ esterase activity tests in Aedes aegypti Larvae.

\begin{tabular}{llllc}
\hline Esterase & Sensitivity & Qualitative & Quantitative & \% \\
\hline Esterase $\alpha$ & Very sensitive & Yellow & $<0,70$ & 91 \\
& Moderate resistant & Greenish blue & $0,70-0,90$ & 9 \\
& Highly resistant & Dark blue & $>0,90$ & 0 \\
\hline Esterase $\beta$ & Very sensitive & Yellow & $0-0,4$ & 43,3 \\
& Moderate resistant & Pink & $0,4-0,6$ & 48 \\
& Highly resistant & Dark pink & $>0,6$ & 8,7 \\
\hline
\end{tabular}




\section{Discussion}

The location of the research is an endemic area of DHF in Pekanbaru City. This area is a densely populated area near the center of Pekanbaru City. A densely populated area is a risk factor for the spread of the dengue virus. A large number of artificial containers both inside and outside people's homes is the reason for a large number of mosquito nests, so dengue cases often occur. Every time a DHF case is found, fogging will be carried out either by the local health office or social organization.

The $\mathrm{LC}_{50}$ value is an indicator of the acute toxicity of a substance, while the $\mathrm{LC}_{99}$ is the diagnostic value for resistance. LC 99 value obtained results $0.185 \mathrm{ppm}$, which means that at this concentration $99 \%$ of Ae. aegypti larvae died. The $\mathrm{LC}_{99}$ value which was compared with the diagnostic value for resistance, according to WHO showed the results of Ae. aegypti larvae were already resistant to temephos (19).

The differences in the evolution of temephos resistance observed in all these colonies may be due, among other factors, to variations in the methodologies used for insecticide exposure, levels of pre-existent resistance to the chemical, frequencies of genes involved in resistance, and to distinct resistance mechanisms with a different mode of inheritance. All this emphasizes the importance of resistance characterization in mosquito populations (13).

Using the right dose of temephos can reduce the risk of developing resistance. Abate containing $1 \%$ Temephos is used at a dose of 10 grams for 100 liters of water with the sprinkling of abate done every three months (23). Insecticide resistance control can be carried out by implementing resistance management, namely monitoring vector susceptibility status, targeted and limited insecticides, insecticides for adult and prepubescent stages, insecticide use rotation (24).

Based on the results of interviews conducted with larva monitoring teams in Payung Sekaki, Pekanbaru City, the teams routinely give abate powder every month to residents. Giving abate powder is thought to affect mosquito larvae's immunity against temephos because it should be possible to give abate powder onceevery three months. One of the factors that influence the rate of development of resistance is the level of selection pressure received by an insect population. Under the same conditions, a population that is subjected to more severe pressure will develop into a resistant population in a shorter time than an insect population that is subjected to weaker selection pressure (25).

The sensitivity test for Ae. aegypti against malathion in DHF endemic areas Payung Sekaki District, Pekanbaru City, showing resistance with a mortality of $28 \%$. This resistance also occur due to the use of the insecticide malathion and other organophosphate for a long time and continuously. Besides, these areas are often subjected to fogging by social organizations with not standard concentrations of malathion.

Based on biochemical assay can be observed that larvae have begun to form metabolically resistant organophosphates both through visual observation and based on the AV value. Two mechanisms can cause metabolic resistance due to the esterase enzyme, quantitatively and qualitatively. Quantitatively, resistance occurs due to the production of too much esterase enzyme caused by concurrent changes in gene expression or co-amplification of $\alpha 2$ (est $\alpha 2)$ and $\beta 2$ (est $\beta 2$ ) esterase genes in amplicons of approximately 28 kilobase pairs (kbp). Meanwhile, qualitatively, resistance occurs due to an increase in the speed of enzyme activity in hydrolyzing organophosphate insecticides (17).

The est $\alpha 2$ and est $\beta 2$ genes are physically very close and have opposite transcription directions. Although there is linear coamplification in the genome, the transcription rates of the two are different. The est $\beta 2$ gene has a transcription rate 2-30 times higher than the esta 2 gene and three times more protein content than gen $\alpha 2$ in the resistant vector's homogenate mass (17).

Apart from these two esterase genes, other genes can cause resistance, namely monooxygenase and glutathione $\mathrm{s}$ transferase (21). This gene is close to the est $\alpha 2$ and est $\beta 2$ genes. The presence of this gene causes the speed of detoxification of organophosphate 
insecticides to be faster because the more genes are amplified, the higher the resistance level. The resistance level is higher because the insecticide is more reactive with esterase than its target. If the esterase concentration is comparable to that of an insecticide, the esterase can sequester/hide the insecticide from the body's metabolic system and hydrolyze it into nontoxic products (16).

Resistance can occur for several reasons. One of the things that cause resistance is the use of insecticides for a long time and a high frequency. Malathion insecticide has been used for approximately 30 years by the DHF Vector Control Program with fogging applications, especially in areas where endemic. Malathion has been used in the dengue eradication program in Indonesia since 1973.

Insect colonies resistant to insecticides are a valuable source for studies on resistance mechanisms. However, the selection process of these insects is extremely laborious. Reports on mosquito colonies resistant to temephos are scarce. The cause of mosquito resistance to a known type of insecticide is due to 3 factors, namely, a decrease in the rate of penetration of the insecticide through the skin or integument, a decrease in the sensitivity of the target site

\section{References}

1. Harapan H, Michie A, Mudatsir M, Sasmono RT, Imrie A. Epidemiology of Dengue Hemorrhagic Fever in Indonesia: Analysis of Five Decades Data from the National Disease Surveillance. BMC Res Notes. 2019;12(1):350. 2. World Health Organization. Dengue and severe dengue. World Health Organization. 2019.

3. Higa Y. Dengue Vectors and Their Spatial Distribution. Trop Med Health. 2011;39(4 Suppl):17-27.

4. Kraemer MUG, Sinka ME, Duda KA, Mylne AQN, Shearer FM, Barker CM, et al. The Global Distribution of the Arbovirus Vectors Aedes aegypti and Ae. Albopictus. Elife. 2015;4(2015):1-18.

5. Harapan H, Michie A, Yohan B, Shu PY, Mudatsir M, Sasmono RT, et al. Dengue Viruses for insecticides on the body of insects such as acetylcholinesterase to organophosphates, and the increase in insecticide detoxification are due to the action of certain enzymes. There are two mechanisms of enzyme changes that cause resistance, excessive production of increasing insecticide metabolism and a change in the catalytic nature of the enzyme to become hypercatalectic (12).

The development of vector population resistance to insecticides is influenced by three main factors, namely genetic, operational, and biological. Resistance will spread rapidly throughout the population if the resistance gene is homozygous dominant (13). The organophosphate group malathion insecticide with the carbamate group bendiocarb insecticide has the same target site, acetylcholinesterase, causing multiple resistance (26).

\section{Acknowledgements}

The authors thank to larvae collector in Payung Sekaki Pekanbaru for helping in larvae collection. This study was funded by reseach grant from Faculty of Medicine, Universitas Riau $2020 \quad$ (Grant no. B/25/UN19.5.1.1.8/PT.01.05/UPPM/2020).

Circulating in Indonesia: A Systematic Review and Phylogenetic Analysis of Data from Five Decades. Reviews in Medical Virology. 2019;29(4):1-17.

6. Buhler C, Winkler V, Runge-Ranzinger S, Boyce R, Horstick O. Environmental Methods for Dengue Vector Control - A Systematic Review and Meta-Analysis. PLoS Negl Trop Dis. 2019;13(7):e0007420.

7. World Health Organization. Dengue Guidelines for Diagnosis, Treatment, Prevention and Control. Geneva: World Health Organization; 2009.

8. Hardjanti A, Indrawati I, Donanti E, Wibowo $\mathrm{H}$, Zulhasril Z. Detection of Insecticide Resistance in Aedes Aegypti to Organophosphate in Pulogadung, East Jakarta. Makara J Heal Res. 2016;19(3):117-20. 
9. Pamella D Moore, Clement J. Wedjou, Tcaunw PBT. Malathion-Induced Oxidative Stress, Cytotoxicity and Genotoxicity in Human Liver Carcinoma (HepG2) Cells. Environ Toxicol. 2010;25(3):221-6.

10. Denholm I, Devine G. Insecticide Resistance. Encycl Biodivers Second Ed. 2013;4:298-307.

11. Lima EP, Paiva MHS, De Arúajo AP, Da Silva ÉVG, Da Silva UM, De Oliveira LN, et al. Insecticide Resistance in Aedes aegypti Populations from Cearáe, Brazil. Parasites and Vectors. 2011;4(1):1-12.

12. Brogdon WG, McAllister JC. Insecticide resistance and vector control. Emerg Infect Dis. 1998;4(4):605-613.

13. Melo-Santos MAV, Varjal-Melo JJM, Araújo AP, Gomes TCS, Paiva MHS, Regis LN, et al. Resistance to the organophosphate temephos: mechanisms, evolution and reversion in an Aedes aegypti laboratory strain from Brazil. Acta Trop. 2010;113(2):180-9.

14. Kandel Y, Vulcan J, Rodriguez SD, Moore E, Chung HN, Mitra S, et al. Widespread insecticide resistance in Aedes aegypti L. PLoS One. 2019;14(2):e0212693.

15. Khanam J, Hossain D, Hosen B, Uddin M, Kabir A, Bari MA. Association of glutathione STransferase theta 1 and mu 1 genes polymorphisms with the susceptibility of myocardial infarction in Bangladesh. Rep Biochem Mol Biol. 2020;9(3):366-372.

16. Mangas I, Estevez J, Vilanova E, França TCC. New Insights on Molecular Interactions of Organophosphorus Pesticides with Esterases. Toxicology. 2017;376:30-43.

17. Hemingway J, Hawkes NJ, McCarroll L, Ranson H. The Molecular basis of insecticide resistance in mosquitoes. Insect Biochem Mol Biol. 2004;34(7):653-65.

18. Rodriguez MM, Bisset JA, Ricardo Y, Perez O, Montada D, Figueredo D, et al. Resistance to organophosphorus insecticides found in Aedes aegypti (Diptera: Culicidae) from Santiago de
Cuba, 1997-2009. Rev Cuba Med Trop. 2010;62(3):217-23.

19. World Health Organization. Instruction for determining the susceptibility or resistance of mosquito larva to insecticide. 1981.

20. World Health Organization. Test procedures for insecticide resistance monitoring in malaria vector mosquitoes. second edition. Second. Geneva: World Health Organization; 2016. 1229.

21. Widiastuti D, Ikawati B, Martini M, Wijayanti N. Biochemical characterization of insecticide resistance and exposure in Aedes aegypti population from wonosobo (a new highland Dengue endemic area), Central Java, Indonesia. Heal Sci J Indones. 2017;8(2).

22. Lee HL. Rapid and simple biochemical methode for detection of insecticide due to elevate esterase activity in Culex quenquefasciatus. Trop Biomed. 1990;7:21-6.

23. George L, Lenhart A, Toledo J, Lazaro A, Han WW, Velayudhan R, et al. CommunityEffectiveness of Temephos for Dengue Vector Control: A Systematic Literature Review. PLoS Negl Trop Dis. 2015;9(9).

24. Corbel V, Guessan R. Distribution, Mechanisms, impact and management of insecticide resistance in Malaria vectors: A pragmatic review. 2013.

25. Fuadzy H, Wahono T, Widawati $M$. Susceptibility of Aedes aegypti larvae against temephos in dengue hemorrhagic fever endemic area Tasikmalaya city. Jurnal Aspirator. 2017;9(1):29-34.

26. Fang Y, Shi WQ, Wu JT, Li YY, Xue JB, Zhang Y. Resistance to pyrethroid and organophosphate insecticides, and the geographical distribution and polymorphisms of target-site mutations in voltage-gated sodium channel and acetylcholinesterase 1 genes in Anopheles sinensis populations in Shanghai, China. Parasit Vectors. 2019;12(1):396. 